\title{
Sistem Pendukung Keputusan Kelompok Untuk menentukan Penerima AGC Award Menggunakan Metode Simple Additive Weighting dan Borda
}

\author{
Arif Tirtana*) \\ Program Studi Teknik Informatika, STIKI Malang \\ Jln. Raya Tidar 100, Kota Malang, 65146, Indonesia \\ email:arif.tirtana@stiki.ac.id
}

Copyright @2019, Politeknik Harapan Bersama, Tegal

\begin{abstract}
PT. Astra International continues to develop into one of the leading group of companies in Indonesia. Currenty its manages six core business namely, automotive, financial, services, heavy equipment, mining, agro-business, infrastructure, logistics, and information techonology. In its operations can bring various impact on enviroment quality, such as the avalaibility of natural resources (water, energy and materials), waste generated in the form of solid, fluid, and air. Therefore ESR Division carry out an assessment of the subsidiary programs to minimize the impact. In this research using SAW method to support the decision making of individual decision, and Borda method to support the group decision making and to determine AGC Award recipient. The decision support system model proposed in this study has proven to solve problems that require individual or group decision-making processes.
\end{abstract}

Abstrak - PT. Astra International terus berkembang menjadi salah satu grup perusahaan terkemuka di Indonesia. Saat ini PT. Astra International bergerak di enam lini bisnis utama yaitu otomotif, jasa keuangan, alat berat dan pertambangan, agribisnis, infrastruktur dan logistik, dan teknologi informasi. Dalam menjalankan operasional perusahaan seringkali memiliki dampak terhadap lingkungan hidup, seperti contoh ketersediaan sumber daya alam (air, energi, material), limbah yang dihasilkan (air, udara, dan padat). Oleh karena itu Divisi ESR melaksanakan program penilaian terhadap anak perusahaan guna mengurangi dampak tersebut. Pada penelitian ini menggunakan metode SAW untuk menunjang pengambilan keputusan individu, dan metode Borda digunakan untuk menunjang proses pengambilan keputusan kelompok. Model sistem pendukung keputusan yang diusulkan dalam penelitian ini terbukti dapat menyelesaikan permasalahan yang membutuhkan proses pengambilan keputusan individu maupun kelompok.

Kata Kunci : Lingkungan, SAW, Borda, SPK

\section{PENDAHULUAN}

Dalam pelaksanaan kegiatan operasional perusahaan seringkali membawa dampak bervariasi utamanya dampak negatif yang berpengaruh terhadap kualitas lingkungan hidup salah satunya ketersediaan sumber daya alam, antara lain: air energi, dan mineral, selain itu dampak negatif lain yang

*) Corresponding Author: (Arif Tirtana)

Email: arif.tirtana@stiki.ac.id ditimbulkan yaitu seringkali adanya limbah yang ditimbulkan, pencemaran air, udara dan tanah yang dapat mengancam keanekaragaman hayati. Oleh karena itu Divisi Environment and Social Responsibility (ESR) PT. Astra International yang dibentuk khusus untuk menangani masalah lingkungan dan tanggung jawab sosial berinisiatif untuk memberikan penghargaan terhadap anak perusahaan yang paling mematuhi regulasi dan perundangan terhadap setiap kegiatan operasional, dan penghargaan tersebut diberi nama Astra Green Company (AGC) Award [1].

Dalam pelaksanaannya, untuk menentukan penerima AGC Award, pertama-tama harus dibentuk tim penilai (assessor) dan melakukan penilaian (assessment) terhadap anak perusahaan. Tim penilai terdiri dari tiga orang penilai yang memiliki kompetensi di bidang lingkungan dan untuk melakukan penilaian diharuskan untuk mengunjungi seluruh anak perusahaan yang tersebar di seluruh Indonesia.

Pada pelaksanaanya, untuk menentukan penerima AGC Award kurang memaksimalkan peran komputer, sehingga membutuhkan waktu yang relatif lama untuk menentukan penerima AGC Award. Sehingga agar pelaksanaan kegiatan tersebut dapat lebih efisien maka perlu dibuat sebuah sistem pendukung keputusan (SPK) yang mampu menghasilkan keputusan secara cepat dan tepat.

Agar dapat memberikan dukungan terhadap pengambil keputusan (decision maker), sistem pendukung keputusan memanfaatkan subsistem manajemen model yang didalamnya terdapat metode kuantitatif agar sistem dapat menghasilkan luaran berupa pernakingan. Salah satu metode yang diguakan pada sistem pendukung keputusan adalah metode multi attribute decision making (MADM) [2]. Salah satu metode yang sering digunakan adalah metode simple additive weightning (SAW). Dipilihnya metode SAW dalam penelitian ini karena metode SAW merupakan metode yang mudah dimengerti [3], memiliki waktu komputasi yang singkat untuk memperoleh hasil [4], dan dapat mendukung proses pengambilan keputusan karena didasarkan pada nilai bobot dan kriteria yang telah ditentukan sebelumnya [5]. Ditunjang dengan metode Borda sebagai metode untuk pengambilan keputusan kelompok. Borda merupakan metode penunjang keputusan kelompok yang mana untuk mendapatkan hasilnya, didapatkan dengan mengalikan nilai preferensi dengan nilai 
bobot dari rangking [6]. Sesuai dengan studi kasus yang dihadapi yang membutuhkan pengambilan keputusan secara kelompok (group decision support) [7].

Tujuan dari penelitian ini adalah untuk melakukan perancangan sistem pendukung keputusan dengan menggunakan kombinasi antara metode SAW dan Borda guna mendukung pengambilan keputusan kelompok untuk menentukan penerima AGC award.

\section{PENELITIAN YANG TERKAIT}

Penelitian terkait sistem pendukung keputusan terdahulu dilakukan dengan topik pembuatan sistem pendukung keputusan yang digunakan untuk menyeleksi pegawai mikro kredit di bidang sales dengan menggunakan metode AHP dan SAW. Pada penelitian tersebut, metode AHP digunakan untuk menentukan nilai bobot pada masing-masing kriteria, sedangkan metode SAW digunakan unutk menghitung nilai preferensi. Pada penelitian tersebut menggunakan sembilan kriteria, antara lain: latar belakang data diri, motivational fit, orientasi layanan, kemampuan interpersonal, orientasi presetasi, kemampuan menjual, kepercayaan diri, dapat dipercaya, dan etos kerja [8].

Penelitian lain terkait SPK dengan judul tema perancanga sistem pendukung keputusan yang digunakan untuk membantu menentukan hasil seleksi pegawai salah satu universitas dengan menggunakan metode perbandingan eksponensial (MPE). Pada penelitian tersebut terdapat dua kegiatan yang dilakukan, yaitu seleksi tenaga pendidik dan seleksi tenaga kependidikan. Pada seleksi tenaga pendidik kriteria yang digunakan yaitu Tes Kemampuan Akademik, Tes Bahasa Inggris, Tes Kompetensi Bidang Teori, Tes Kompetensi Bidang Praktek, dan Tes Wawancara. Sedangkan untuk seleksi Tenaga Kependidikan menggunakan kriteria antara lain: Tes Kemampuan Akademik, Tes Bahasa Inggris, Tes Kemampuan Bidang Teori, dan Tes Wawancara [9].

Penelitian lain terkait SPK dengan topik pemilihan prgram studi pada salah satu perguruan tinggi dengan menggunakan metode TOPSIS, menggunakan kriteria yaitu kemampuan akademik mata pelajaran seperti matematika, Bahasa Indonesia, Bahasa Inggris, Kimia, Fisika, dan Biologi [10]. Penelitian lain terkait SPK yaitu dengan topik pemilihan tema tugas akhir mahasiswa dengan menggunakan metode analytic network process (ANP), pada penelitian tersebut menggunakan beberapa kriteria antara lain nilai mata kuliah, nilai kompetensi, dan nilai peminatan [11].

Penelitian terkait sistem pendukung keputusan kelompok yaitu dengan tema pembuatan sistem pendukung keputusan kelompok untuk menentukan dosen berprestasi pada salah satu kampus swasta di Kota Purwokterto menggunakan kombinasi antara metode TOPSIS dan Borda. [12]. Dari beberapa kajian penelitian sebelumnya pada penelitian ini menggunakan kombinasi antara metode SAW dan Borda.

\section{METODE PENELITIAN}

Penelitian ini bertujuan untuk memodelkan Sistem Pendukung Keputusan Kelompok Untuk Menentukan Penerima AGC Award dengan menggunakan metode SAW dan Borda. Studi kasus diambil dari PT. Astra International Tbk. Pada penelitian ini menggunakan data hasil penilaian dari tim penilai yang memiliki wewenang untuk melakukan penilaian AGC Award. Terdapat 6 alternatif dan 4 kriteria yang akan digunakan. Adapun perancangan arsitektur SPK untuk menentukan penerima AGC Award dapat dilihat pada Gbr 1 .

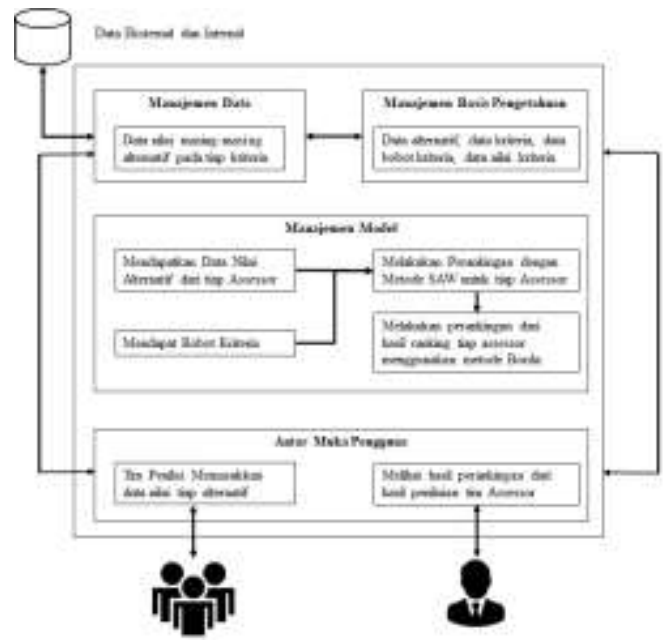

Gbr 1. Arsitektur SPKK Untuk Menentukan Penerima AGC Award [13]

Dari hasil wawancara yang dilakukan, terdapat 4 kriteria yang digunakan untuk menentukan penerima AGC Award, antara lain: Green Strategy, Green Process, Green Product, dan Green Employee. Green Strategy adalah kriteria yang mencakup proses perencanaan perusahaan yang menganalisis implikasi kondisi internal. Green Process adalah kriteria yang menjadi pedoman dalam membuat desain proses peralatan, infrastruktur, dan area kerja lainnya. Green Product adalah kriteria yang menjadi perencanaan setiap anak perusahaan. Green Employee adalah identifikasi dan menentapkan standar kompetensi kerja untuk karyawan di area atau proses yang berdampak pada lingkungan, kesehatan dan keselamatan kerja. Untuk perhitungan bobot kriteria didapat melalui data penilaian yang telah dilakukan sebelumnya, tabel kriteria beserta dengan bobot kriteria ditunjukkan pada tabel 1 .

Selanjutnya menggabungkan seluruh kriteria, alternatif dan kriteria pada tabel data hasil penilaian alternatif. Data penilaian alternatif oleh assessor pertama, kedua, dan ketiga ditunjukkan berturut-turut pada tabel 2,3, dan 4 .

TABEL I

TABEL KRITERIA DAN BOBOT KRITERIA

\begin{tabular}{|c|c|c|}
\hline Nama Kriteria & Notasi & Bobot Kriteria \\
\hline Green Strategy & $\mathrm{C} 1$ & 0,258 \\
\hline Green Process & $\mathrm{C} 2$ & 0,516 \\
\hline Green Product & $\mathrm{C} 3$ & 0,129 \\
\hline Green Employee & $\mathrm{C} 4$ & 0,097 \\
\hline
\end{tabular}

TABEL II

TABEL PENILAIAN ASSESSOR 1

\begin{tabular}{|c|c|c|c|c|}
\hline ID & C1 & C2 & C3 & C4 \\
\hline A1 & 800 & 1392 & 352 & 260 \\
\hline A2 & 519 & 899 & 278 & 300 \\
\hline A3 & 768 & 1231 & 380 & 275 \\
\hline A4 & 549 & 1294 & 430 & 300 \\
\hline A5 & 620 & 852 & 225 & 280 \\
\hline A6 & 730 & 1236 & 380 & 255 \\
\hline
\end{tabular}


TABEL III

TABEL PENILAIAN ASSESSOR 2

\begin{tabular}{|c|c|c|c|c|}
\hline ID & C1 & C2 & C3 & C4 \\
\hline A1 & 800 & 1376 & 342 & 290 \\
\hline A2 & 705 & 1225 & 365 & 280 \\
\hline A3 & 595 & 1071 & 360 & 235 \\
\hline A4 & 700 & 1359 & 450 & 300 \\
\hline A5 & 565 & 1048 & 279 & 260 \\
\hline A6 & 790 & 1334 & 380 & 255 \\
\hline
\end{tabular}

TABEL IV

TABEL PENILAIAN ASSESSOR 3

\begin{tabular}{|c|c|c|c|c|}
\hline ID & C1 & C2 & C3 & C4 \\
\hline A1 & 650 & 954 & 332 & 215 \\
\hline A2 & 605 & 1056 & 358 & 200 \\
\hline A3 & 800 & 1337 & 325 & 300 \\
\hline A4 & 665 & 1359 & 450 & 300 \\
\hline A5 & 410 & 852 & 225 & 230 \\
\hline A6 & 555 & 1221 & 327 & 235 \\
\hline
\end{tabular}

\section{HASIL DAN PEMBAHASAN}

\section{A. Proses Perhitungan}

Langkah dalam pertama metode SAW untuk menentukan penerima AGC Award pada penilaian tiap assessor yaitu melakukan normalisasi matriks keputusan yang didapatkan dari tabel 2,3, dan 4 dengan menggunakan persamaan 1 .

Melakukan normalisasi matriks keputusan yang didapatkan menggunakan persamaan 1 dibawah ini.

$r_{\mathrm{i} \text { ij }}=\left\{\begin{array}{l}\frac{x_{\mathrm{if}}}{\max _{\mathrm{i}} x_{\mathrm{i} f}} \text { Jika } \mathrm{j} \text { adalah atribut keuntungan (benefit) } \\ \frac{\min _{\mathrm{i}} x_{\mathrm{i} f}}{x_{\mathrm{if}}} \text { Jika j adalah atribut biaya (cost) }\end{array}\right.$

Dimana:

$r_{\mathrm{i} \text { i }}$ adalah rating kinerja ternormalisasi

$\max _{i}$ adalah nilai maksimal dari setiap baris dan kolom

$\min _{\mathrm{i}}$ adalah nilai minimal dari setiap baris dan kolom

$x_{\text {if }}$ adalah baris dan kolom dari matriks

Semua kriteria yang digunakan dalam penelitian ini termasuk dalam kategori benefit, sehingga untuk proses normalisasi matriks menggunakan rumus $\frac{x_{x_{j}}}{\max _{1} x_{1 j}}$.

Tahap selanjutnya setelah melakuka normalisasi matriks yaitu menghitung nilai preferensi dengan menggunakan persamaan 2 .

$V_{i}=\sum_{j=1}^{n} w_{j} r_{i j}$

Dimana:

$V_{i}=$ Nilai akhir dari alternatif

$w_{\tilde{j}}=$ Bobot kriteria yang telah ditentukan

$r_{\mathrm{i} \text { ij }}=$ Rating kerja ternormalisasi

Hasil keputusan sistem yang didapatkan menggunakan metode SAW dari penilaian assesssor 1,2, dan 3 berturut-turut dapat dilihat pada tabel 5, 6 dan 7. Kemudian dari hasil perhitungan ketiga assessor tersebut dilakukan perankingan dengan metode Borda sebagai metode untuk mendukung pengambilan keputusan. Hasil perhitungan metode Borda digambarkan pada tabel 8. Dari hasil perhitungan kelompok dengan menggunakan metode Borda didapatkan bahwa A4 menempati ranking 1 sehingga bisa disimpulkan bahwa A4 berhak untuk mendapat penghargaan AGC Award.

TABEL V

HASIL PERHITUNGAN ASSESSOR 1

\begin{tabular}{|c|c|c|}
\hline Alternatif & Nilai V & Peringkat \\
\hline A1 & 0.964 & 1 \\
\hline A2 & 0.681 & 5 \\
\hline A3 & 0.907 & 2 \\
\hline A4 & 0.883 & 4 \\
\hline A5 & 0.674 & 6 \\
\hline A6 & 0.890 & 3 \\
\hline
\end{tabular}

TABEL VI

HASIL PERHITUNGAN ASSESSOR 2

\begin{tabular}{|c|c|c|}
\hline Alternatif & Nilai V & Peringkat \\
\hline A1 & 0.966 & 1 \\
\hline A2 & 0.882 & 4 \\
\hline A3 & 0.773 & 5 \\
\hline A4 & 0.961 & 2 \\
\hline A5 & 0.739 & 6 \\
\hline A6 & 0.946 & 3 \\
\hline
\end{tabular}

TABEL VII

HASIL PERHITUNGAN ASSESSOR 3

\begin{tabular}{|c|c|c|}
\hline Alternatif & Nilai V & Peringkat \\
\hline A1 & 0.737 & 5 \\
\hline A2 & 0.763 & 4 \\
\hline A3 & 0.956 & 2 \\
\hline A4 & 0.956 & 1 \\
\hline A5 & 0.595 & 6 \\
\hline A6 & 0.812 & 3 \\
\hline
\end{tabular}

TABEL VIII

HASIL PERHITUNGAN KELOMPOK

\begin{tabular}{|c|c|c|c|c|c|c|c|c|}
\hline \multirow{2}{*}{ Alternatif } & \multicolumn{6}{|c|}{ Ranking } & \multirow{2}{*}{$\begin{array}{c}\text { Poin } \\
\text { Borda }\end{array}$} & \multirow{2}{*}{$\begin{array}{l}\text { Nilai } \\
\text { Borda }\end{array}$} \\
\hline & 1 & 2 & 3 & 4 & 5 & 6 & & \\
\hline A1 & 11.577 & 0 & 0 & 0 & 1.473 & 0 & 13.050 & 0.225 \\
\hline $\mathbf{A 2}$ & 0 & 0 & 0 & 6.646 & 1.362 & 0 & 8.008 & 0.138 \\
\hline A3 & 0 & 9.558 & 0 & 0 & 1.545 & 0 & 11.104 & 0.192 \\
\hline A4 & 5.739 & 4.807 & 0 & 2.648 & 0 & 0 & 13.194 & 0.228 \\
\hline A5 & 0 & 0 & 0 & 0 & 0 & 2.008 & 2.008 & 0.035 \\
\hline A6 & 0 & 0 & 10.595 & 0 & 0 & 0 & 10.595 & 0.183 \\
\hline $\begin{array}{l}\text { Bobot } \\
\text { Borda }\end{array}$ & 6 & 5 & 4 & 3 & 2 & 1 & 57.958 & \\
\hline
\end{tabular}




\section{B. Pengujian Sensitivitas Kriteria}

Proses pengujian sensitivitas kriteria bertujuan untuk mengetahui kriteria mana yang paling sensitif terhadap hasil nilai preferensi [14] yang dihasilkan oleh perhitungan metode SAW. Proses pengujian dilakukan dengan cara menambahkan dan mengurangi bobot masing-masing kriteria berturut-turut sebesar $-20 \%,-10 \%, 0 \%,+10 \%$, dan $20 \%$ [15]. Adapun hasilnya sebagai berikut pada tabel 9 hingga tabel 12 .

TABEL IX

HASIL PERHITUNGAN UJI SENSIVITAS PADA C1

\begin{tabular}{|l|l|l|l|l|l|l|l|l|l|l|}
\hline \multicolumn{2}{|c|}{ C1(-20\%) } & \multicolumn{2}{c|}{ C1(-10\%) } & \multicolumn{2}{c|}{ C1(0\%) } & \multicolumn{2}{c|}{ C1(+10\%) } & \multicolumn{2}{c|}{ C1(+20\%) } \\
\hline 0.9121 & 1 & 0.9379 & 1 & 0.9637 & 1 & 0.9895 & 1 & 1.0153 & 1 \\
\hline 0.6476 & 5 & 0.6643 & 5 & 0.6810 & 5 & 0.6978 & 5 & 0.7145 & 5 \\
\hline 0.8574 & 2 & 0.8821 & 2 & 0.9069 & 2 & 0.9317 & 2 & 0.9565 & 2 \\
\hline 0.8473 & 3 & 0.8650 & 4 & 0.8827 & 4 & 0.9004 & 4 & 0.9181 & 4 \\
\hline 0.6338 & 6 & 0.6538 & 6 & 0.6738 & 6 & 0.6938 & 6 & 0.7138 & 6 \\
\hline 0.8430 & 4 & 0.8665 & 3 & 0.8900 & 3 & 0.9136 & 3 & 0.9371 & 3 \\
\hline
\end{tabular}

TABEL $X$

HASIL PERHITUNGAN UJI SENSIVITAS PADA C2

\begin{tabular}{|c|c|c|c|c|c|c|c|c|c|}
\hline \multicolumn{2}{|c|}{$\mathbf{C 2 ( - 2 0 \% )}$} & \multicolumn{2}{c|}{$\mathbf{C 2 ( - 1 0 \% )}$} & \multicolumn{2}{c|}{$\mathbf{C 2 ( 0 \% )}$} & \multicolumn{2}{c|}{$\mathbf{C 2 ( + 1 0 \% )}$} & \multicolumn{2}{c|}{ C2(+20\%) } \\
\hline 0.8605 & 1 & 0.9121 & 1 & 0.9637 & 1 & 1.0153 & 1 & 1.0669 & 1 \\
\hline 0.6144 & 5 & 0.6477 & 5 & 0.6810 & 5 & 0.7144 & 5 & 0.7477 & 5 \\
\hline 0.8157 & 2 & 0.8613 & 2 & 0.9069 & 2 & 0.9525 & 2 & 0.9982 & 2 \\
\hline 0.7868 & 4 & 0.8348 & 4 & 0.8827 & 4 & 0.9307 & 4 & 0.9787 & 4 \\
\hline 0.6106 & 6 & 0.6422 & 6 & 0.6738 & 6 & 0.7054 & 6 & 0.7370 & 6 \\
\hline 0.7984 & 3 & 0.8442 & 3 & 0.8900 & 3 & 0.9359 & 3 & 0.9817 & 3 \\
\hline
\end{tabular}

TABEL XI

HASIL PERHITUNGAN UJI SENSIVITAS PADA C3

\begin{tabular}{|c|c|c|c|c|c|c|c|c|c|}
\hline \multicolumn{2}{|c|}{$\mathbf{C 3 ( - 2 0 \% )}$} & \multicolumn{2}{c|}{$\mathbf{C 3 ( - 1 0 \% )}$} & \multicolumn{2}{c|}{ C3(0\%) } & \multicolumn{2}{c|}{ C3(+10\%) } & \multicolumn{2}{c|}{ C3(+20\%) } \\
\hline 0.9425 & 1 & 0.9531 & 1 & 0.9637 & 1 & 0.9742 & 1 & 0.9848 & 1 \\
\hline 0.6643 & 5 & 0.6727 & 5 & 0.6810 & 5 & 0.6894 & 5 & 0.6977 & 5 \\
\hline 0.8841 & 2 & 0.8955 & 2 & 0.9069 & 2 & 0.9183 & 2 & 0.9297 & 2 \\
\hline 0.8569 & 4 & 0.8698 & 4 & 0.8827 & 4 & 0.8956 & 4 & 0.9085 & 4 \\
\hline 0.6603 & 6 & 0.6671 & 6 & 0.6738 & 6 & 0.6806 & 6 & 0.6873 & 6 \\
\hline 0.8672 & 3 & 0.8786 & 3 & 0.8900 & 3 & 0.9014 & 3 & 0.9128 & 3 \\
\hline
\end{tabular}

TABEL XII

HASIL PERHITUNGAN UJI SENSIVITAS PADA C4

\begin{tabular}{|c|c|c|c|c|c|c|c|c|c|}
\hline \multicolumn{2}{|c|}{$\mathbf{C 4 ( - 2 0 \% )}$} & \multicolumn{2}{c|}{$\mathbf{C 4 ( - 1 0 \% )}$} & \multicolumn{2}{c|}{$\mathbf{C 4 ( 0 \% )}$} & \multicolumn{2}{c|}{$\mathbf{C 4 ( + 1 0 \% )}$} & \multicolumn{2}{c|}{$\mathbf{C 4 ( + 2 0 \% )}$} \\
\hline 0.9469 & 1 & 0.9553 & 1 & 0.9637 & 1 & 0.9721 & 1 & 0.9805 & 1 \\
\hline 0.6616 & 5 & 0.6713 & 5 & 0.6810 & 5 & 0.6907 & 5 & 0.7004 & 5 \\
\hline 0.8891 & 2 & 0.8980 & 2 & 0.9069 & 2 & 0.9158 & 2 & 0.9247 & 2 \\
\hline 0.8633 & 4 & 0.8730 & 4 & 0.8827 & 4 & 0.8924 & 4 & 0.9021 & 4 \\
\hline 0.6557 & 6 & 0.6648 & 6 & 0.6738 & 6 & 0.6829 & 6 & 0.6919 & 6 \\
\hline 0.8736 & 3 & 0.8818 & 3 & 0.8900 & 3 & 0.8983 & 3 & 0.9065 & 3 \\
\hline
\end{tabular}

Dari pengujian sensitivitas kriteria yang telah dilaksanakan, didapatkan bahwa kriteria yang paling bersifat sensitif terhadap hasil perangkingan adalah $\mathrm{C} 1$. Hal tersebut dapat menjadi masukan bagi asesor apabila ingin menaikkan nilai preferensi hasil perhitungan metode SPK, dapat merubah bobot dari $\mathrm{C} 1$.

\section{KESIMPULAN}

Penelitian ini bertujuan untuk melakukan perancangan sistem pendukung keputusan kelompok yang berguna untuk membantu tim asesor dalam menentukan penerima AGC Award menggunakan metode SAW dan Borda. Untuk hasil perhitungan SAW dapat menunjukkan hasil perankingan untuk masing-masing assessor. Untuk hasil perhitungan Borda menunjukkan bahwa metode Borda sesuai dengan kebutuhan yakni dapat digunakan menentukan penerima AGC Award sesuai dengan hasil perhitungan dari tim assessor. A4 menempati peringkat 1, sehingga A4 berhak mendapat AGC Award. Dari pengujian sensitivitas kriteria didapatkan bahwa apabila tim penilai ingin meningkatkan nilai preferensi, dapat merubah bobot dari kritera C1 yaitu Green Strategy.

Saran untuk pengembangan penelitian selanjutnya, untuk pengambilan keputusan individu dapat menggunakan metode Multi Attribute Decision Making (MADM) yang lain seperti contoh Preference Ranking Organization Method For Enrichment Evaluation (PROMETHEE) yang memungkinkan memiliki hasil yang berbeda.

\section{UCAPAN TERIMA KASIH}

Penulis mengucapkan banyak terima kasih kepada STIKI Malang atas fasilitas yang digunakan oleh penulis dalam menyelesaikan penelitian ini.

\section{DAFTAR PUSTAKA}

[1] A. International, “Astra International Annual Report 2016,” 2016

[2] Z. Xu, Uncertain Multi Attribute Decision Making Methods and Applications. Springer, 2015.

[3] I. N. Hanifah, "Sistem Pendukung Keputusan Pemilihan Guru Berprestasi dengan Simple Additive Weighting," 2013.

[4] A. W. Saw and E. Ismanto, "Sistem Pendukung Keputusan Penerimaan Karyawan Dengan Metode Simple SATIN - Sains dan Teknologi Informasi Sistem Pendukung Keputusan Penerimaan Karyawan Dengan Metode Simple Additive Weighting ( SAW )," no. March, 2018.

[5] D. C. Hartini, E. L. Ruskan, A. Ibrahim, J. Sistem, I. Fakultas, and I. Komputer, "Sistem Pendukung Keputusan Pemilihan Hotel Di Kota Palembang Dengan Metode Simple Additive Weighting (SAW)," vol. 5, no. 1 , pp. 546-565, 2013.

[6] A. H. P. D. A. N. Borda, "GDSS PENILAIAN KINERJA DAN PERINGKAT GURU,” vol. 1, pp. 91-104, 2017.

[7] D. Apriliani, K. Adi, and R. Gernowo, "Implementasi Metode Promethee dan Borda Dalam Sistem Pendukung Keputusan Pemilihan Lokasi Pembukaan Cabang Baru Bank," J. Sist. Inf. Bisnis, vol. 02, pp. 145-150, 2015

[8] S. Kasus, B. Mandiri, C. Tulungagung, G. Firdana, A. A. Soebroto, and N. Hidayat, "Pegawai Mikro Kredit Sales ( Mks ) Dengan Metode Analytical Hierachy Process - Weighted Product ( Ahp-Wp )," pp. 112.

[9] R. Purwanto, "Rancang Bangun Decision Support System (DSS) untuk Membantu Menentukan Hasil Seleksi Pegawai pada Politeknik Negeri Cilacap dengan Menggunakan Metode Perbandingan Eksponensial (MPE)," vol. 03, no. 02, pp. 190-199, 2018.

[10] F. A. Setyaningsih, "Analisis Kinerja Technique For Order Preference By Similarity To Ideal Solution (TOPSIS) Untuk Pemilihan Program Studi," J. Inform. J. Pengemb. IT, vol. 2, no. 2, pp. 43-46, 2017.

[11] D. Nurlaila, D. Supriyadi, and A. E. Amalia, "Penerapan Metode Analytic Network Process (ANP) Untuk Pendukung Keputusan 
Pemilihan Tema Tugas Akhir (Studi Kasus: Program Studi S1 Informatika ST3 Telkom)," J. Inform. J. Pengemb. IT, vol. 2, no. 2, pp. $63-68,2017$.

[12] M. Hamka and S. A. Wibowo, "Sistem Pendukung Keputusan Kelompok Penentuan Dosen Berprestasi Di Universitas Muhammadiyah Purwokerto Sistem Pendukung Keputusan Kelompok Penentuan Dosen Berprestasi Di Universitas Muhammadiyah Purwokerto," no. December 2014, pp. 0-5, 2018.
[13] R. Sharda, D. Delen, and E. Turban, Business Intelligence and Analytics: Systems for Decision Support. 2014.

[14] S. Kusumadewi, "Sensitivity Analysis of Multi-Attribute Decision Making Methods in Clinical Group Decision Support System," pp. 301-304, 2007.

[15] W. Yusnaeni and R. Ningsih, "Uji Sensitifitas Metode TOPSIS , SAW dan WP untuk Menentukan,”pp. 19-25, 2018. 